\title{
Application of dithiocarbamate resin-metal complexes as stationary phases in gas chromatography
}

\author{
Chia-Fu Yeh, Sun-Dsong Chyueh, Wei-Shi Chen, Jia-Der Fang and Chuen-Ying Liu \\ Department of Chemistry, National Taiwan University, Roosevelt Road, Section 4, Taipei (Taiwan)
}

(First received July 13th, 1992; revised manuscript received October 20th, 1992)

\begin{abstract}
A chelating resin with dithiocarbamate functional groups to which silica gel was used as a matrix and silanes were used with diamino functional groups as a spacer was synthesized. The structure and the conversion of functional groups of the resin were confirmed by IR spectra and elemental analysis. The influence of $\mathrm{pH}$ on the adsorption of the resin for metal ions was also examined. The resin under optimum pH conditions formed a 1:1 metal complex with copper ion. The affinity of metal ions toward the synthesized resin decreased in the order $\mathbf{H g}(\mathbf{I I})>\mathbf{C u}(\mathbf{I I})>\mathbf{C d}(\mathbf{I I})>\mathbf{Z n}($ II). The resin exhibited efficient complexation of transition metal cations. The cadmium, copper and zinc complexes were investigated for application as stationary phase for the gas chromatographic analysis of dialkyl sulphides. The material was packed in a $2.1 \mathrm{~m} \times 3.2 \mathrm{~mm}$ I.D. spiral glass column. Factors affecting the retention and sample selectivity were also studied. A shorter retention time and sharp peaks were obtained when ammonia was introduced into the mobile phase. At an oven temperature of $100^{\circ} \mathrm{C}$, a flow-rate of $60 \mathrm{ml} \mathrm{min}^{-1}$ and use of a flame ionization detector, the analysis of dialkyl sulphides showed that the copper resin complex as the stationary phase gave the best results. The stationary phase was also used for the separation of dialkyl sulphide from a hydrocarbon mixture.
\end{abstract}

\section{INTRODUCTION}

Dithiocarbamates and their derivatives are valuable reagents for the separation and photometric determination of heavy metals. Previous literature on their analytical applications is extensive [1]. The immobilization of such groups, either on a polymer or on a silica matrix, can convert them into useful metal-chelating sorbents. These can be used for the selective removal of heavy metal ions from aqueous solutions [2] and, in particular, for ligand-exchange chromatography (LEC). LEC is a process in which complex-forming compounds are separated through the formation and breaking up of labile coordinate bonds to a central metal atom, coupled with partitioning between a mobile and a stationary phase. It separates ligands by causing them to

Correspondence to: C.-Y. Liu, Department of Chemistry, National Taiwan University, Roosevelt Road, Section 4, Taipei, Taiwan. change places around metal ions. The exchange can occur in either the stationary or the mobile phase.

LEC is one of the most powerful techniques among the variety of commonly used separation methods for resolving complex-forming substances. Much work has been done previously since its introduction in the early 1960s on the separation of isomers or homologues of amines, phenols, amino acids and other organic ligands containing nitrogen or oxygen atoms [3]. Some limitations in operating an LEC system through use of a liquid mobile phase exist, even though many types of samples or stationary phase can be selected and modification of the mobile phase is easy and effective. Additionally, detection is sometimes difficult if a UV-visible detector is being used. A stronger complexing group, dithiocarbamates, was introduced in this work into silica as the LEC sorbent, as a result of taking into account these disadvantages. So far, only a few workers have used the potential of dithiocarbamate resins as LEC sorbents $[4,5]$. The mobile 
phase they used was, however, a liquid phase. Although the main principle of LEC is valid both for liquid chromatography in all its versions and for gas chromatography, the latter technique often cannot employ the same coordination systems. In liquid chromatography, solvent molecules or specially added components of the mobile phase actively compete with the solute species for vacant positions in the coordination sphere of the complexing metal ion. A real ligand exchange thus proceeds in the moving chromatographic zone of each solute. In contrast, nitrogen, helium or the other inert gases used in gas chromatography as mobile phases are not able to displace ligands from their sorption complexes. Only extremely labile complexes that easily dissociate at moderate temperatures can therefore be employed in gas chromatographic systems [6].

The complexing behaviour and the stability of the synthesized resin were studied in this investigation. The feasibility of using metal-loaded sorbents as stationary phases for the separation of dialkyl sulphides with a gaseous mobile phase, namely ligand-exchange gas chromatography, was also investigated.

\section{EXPERIMENTAL}

\section{Apparatus}

Infrared spectra of the synthesized resin and its metal complexes in $\mathrm{KBr}$ were recorded in the range 4000-200 cm-' on an IR spectrophotometer (Perkin-Elmer 983). The electron paramagnetic resonance (EPR) spectra of the metal-resin complexes in the solid state were recorded at room temperature on an EPR spectrophotometer (Bruker ESP $300)$.

A gas chromatograph (Shimadzu Model GC-9A) equipped with a hydrogen flame ionization detector and integrator (Shimadzu Chromatopac C-R2AX) was used. Pure nitrogen and nitrogen containing 5 and $10 \%(\mathrm{v} / \mathrm{v})$ of ammonia were used as carrier gases at flow-rates in the range $20-90 \mathrm{~mL} \mathrm{~min}^{-1}$. The column temperature varied in the range $70-100^{\circ} \mathrm{C}$.

\section{Chemicals}

Most chemicals were of analytical-reagent grade from Merck (Darmstadt, Germany). Dialkyl sulphides were supplied by Aldrich (Milwaukee, WI, USA).

\section{Synthesis of sorbents}

Silica gel (50 mesh) was ground, sieved and refluxed in 2-propanol for $2 \mathrm{~h}$, then washed successively with water and acetone. A solution of $\mathrm{N}-[3-$ (trimethoxy silyl)propyl]ethylenediamine $(5 \mathrm{ml})$ in toluene $(100 \mathrm{ml})$ was added to this purified silica (4 $\mathrm{g}$ ); after reaction at $75^{\circ} \mathrm{C}$ with acetic acid as catalyst for $3 \mathrm{~h}$, the resulting modified silica was washed successively with 2-propanol, water and acetone and then dried overnight under vacuum at $60^{\circ} \mathrm{C}$. A solution of carbon disulphide $(10 \mathrm{ml})$ and potassium tert.-butoxide $(6 \mathrm{~g})$ in toluene $(300 \mathrm{ml})$ was added to the above product. The mixture was stirred for $6 \mathrm{~h}$ at $60^{\circ} \mathrm{C}$. The product was called S-DTC.

\section{Preparation of metal-loaded sorbents}

A 3-g amount of the synthesized resin was suspended in $0.1 M \mathrm{Cd}(\mathrm{II}), \mathrm{Cu}(\mathrm{II}), \mathrm{Hg}$ (II) or $\mathrm{Zn}$ (II) solution $(90 \mathrm{ml})$. Acetic acid-sodium acetate buffer (1 $\mathrm{M}, \mathrm{pH} \mathrm{5)}(10 \mathrm{ml})$ was added and each mixture was mechanically shaken for $4 \mathrm{~h}$. The metal-loaded phases were collected on glass filters and washed with pure water (>16 M $\Omega, 100 \mathrm{ml}$ ) and dried for 2 $\mathrm{h}$ in a vacuum oven.

\section{Analytical application}

Gas chromatography was carried out on $2.1 \mathrm{~m} \times$ $3.2 \mathrm{~mm}$ I.D. spiral glass columns which were packed under ultrasonic conditions with the synthesized resin metal complexes. The columns were conditioned for $5 \mathrm{~h}$ before measurements were taken.

\section{RESULTS AND DISCUSSION}

\section{Characterization}

The composition and structures of the synthesized resin were characterized after each step of the synthesis by elemental analysis and IR spectrometry. The functionality of ethylenediamine to the silica gel was $1.55 \mathrm{mmol} \mathrm{g}^{-1}$ and that of dithiocarbamate to the above product was $1.41 \mathrm{mmol} \mathrm{g}$-i. The elemental analysis data are given in Table I.

The $\mathrm{p} K_{\mathrm{a}}$ values of the synthesized resin were determined by potentiometric titration and calculated by a modification of Bjerrum's method. The $\mathrm{p} K_{\mathrm{a}}$ values were 7.0 and 9.4 (Table II). By comparison with the $\mathrm{p} K_{\mathrm{a}}$ values of some protonated amine [7] and dithiocarbamate compounds [8], the former 
TABLE I

ELEMENTAL ANALYSIS DATA OF CHELATING RESINS WITH SILICA GEL AS MATRIX

\begin{tabular}{|c|c|c|c|c|c|c|c|c|c|}
\hline \multirow[t]{2}{*}{ Resin } & \multicolumn{2}{|l|}{$\mathrm{C}$} & \multirow{2}{*}{$\begin{array}{l}\mathbf{H} \\
(\%)\end{array}$} & \multicolumn{2}{|l|}{$\mathrm{N}$} & \multicolumn{2}{|l|}{$\mathbf{S}$} & \multirow{2}{*}{$\begin{array}{l}\text { EN group } \\
\left(\mathrm{mm01} \mathrm{g}^{-1}\right)\end{array}$} & \multirow{2}{*}{$\begin{array}{l}\text { DTC group } \\
\left(\mathrm{mmol}^{-1}\right)\end{array}$} \\
\hline & $\%$ & $\mathrm{mmol} \mathrm{g}^{-1}$ & & $\%$ & $\mathrm{mmol} \mathrm{g}^{-1}$ & $\%$ & $\mathrm{mmol} \mathrm{g}^{-1}$ & & \\
\hline S-EN & 10.35 & 9.03 & 2.31 & 4.35 & 3.10 & - & - & 1.55 & - \\
\hline S-DTC & 13.41 & 11.17 & 3.30 & 4.46 & 3.18 & 9.03 & 2.82 & 1.59 & 1.41 \\
\hline
\end{tabular}

valve can be concluded possibly to be the dissociation constant of the $\mathrm{NH}_{2}{ }^{+}$group and the latter the dissociation constant of the $-\mathrm{NCS}_{2} \mathbf{H}$ group of $\mathrm{S}$ DTC resin. The results are reasonable as the steric hindrance is larger in the resin, even though the $\mathrm{p} K_{\mathrm{a}}$ values for the resin are higher than those for the monomeric compounds.

The adsorption capacities of the resin for Cd(II), $\mathrm{Cu}(\mathrm{II}), \mathbf{H g}(\mathrm{II})$ and $\mathbf{Z n}(\mathrm{II})$ were measured at various $\mathrm{pH}$ values and the results are shown in Fig. 1. At the optimum $\mathrm{pH}$, the adsorption capacities of S-DTC for $\mathrm{Cd}(\mathrm{II}), \mathrm{Cu}$ (II), $\mathrm{Hg}$ (II) and $\mathrm{Zn}(\mathrm{II})$ were 0.63 , $1.12,3.06$ and $0.43 \mathrm{mmol} \mathrm{g}^{-1}$, respectively. The resin presumably formed a 1:1 metal complex with copper ion and water molecules might be ligands for the unsaturated coordination site of the copper ion. The affinity of metal ions toward the synthesized resin decreased in the order $\mathrm{Hg}(\mathrm{II})>\mathrm{Cu}(\mathrm{II})$ $>\mathrm{Cd}(\mathrm{II})>\mathrm{Zn}(\mathrm{II})$ on the basis of the sorptive capacity. This order was coincident with that for the analogous complexes of the monomeric dithiocar-

TABLE II

$\mathrm{p} \boldsymbol{K}$ VALUES OF SOME PROTONATED AMINE AND DITHIOCARBAMATE COMPOUNDS

\begin{tabular}{lrll}
\hline Species & $\mathrm{p} K_{\mathrm{a}}$ & Species & $\mathrm{p} K_{\mathrm{a}}$ \\
\hline $\mathrm{NH},+$ & $9.24^{\prime \prime}$ & $\mathrm{Me}_{2} \mathrm{NCS}_{2} \mathrm{H}$ & $3.66^{b}$ \\
$n-\mathrm{BuNH}_{3}+$ & $10.60^{a}$ & $\mathrm{Et}_{2} \mathrm{NCS}_{2} \mathrm{H}$ & $4.04^{b}$ \\
$\mathrm{Me}_{2} \mathrm{NH}_{2}^{+}$ & $10.77^{+}$ & $n-\mathrm{Pr}_{2} \mathrm{NCS}_{2} \mathrm{H}$ & $4.79^{b}$ \\
${ }^{+} \mathrm{NH}_{3} \mathrm{CH}_{2} \mathrm{CH}_{2} \mathrm{NH}_{3}{ }^{+} \mathrm{p} K_{1} 6.95 ”$ & $n-\mathrm{Bu}_{2} \mathrm{NCS}_{2} \mathrm{H}$ & $5.19^{b}$ \\
& $\mathrm{p} K_{2} 9.93^{\prime \prime}$ & & \\
$\mathrm{NH}_{2}{ }^{+}$of S-DTC & 9.4 & $-\mathrm{NCS}_{2} \mathrm{H}$ of S-DTC 7.0 \\
\hline
\end{tabular}

${ }^{a}$ Ref. 7.

b Ref. 8 . bamate in aqueous solution [8]. Hence the fixation of the dithiocarbamate group on the silica surface does not lead to substantial changes in the complexing properties of its functional groups. The relatively high uptake of mercury by the resin might be attributed to the additional complexing power of the two nitrogen atoms of the spacer. The capacity of the resin for each metal ion nearly approached saturation in the medium in the $\mathrm{pH}$ range 4-5, ex-

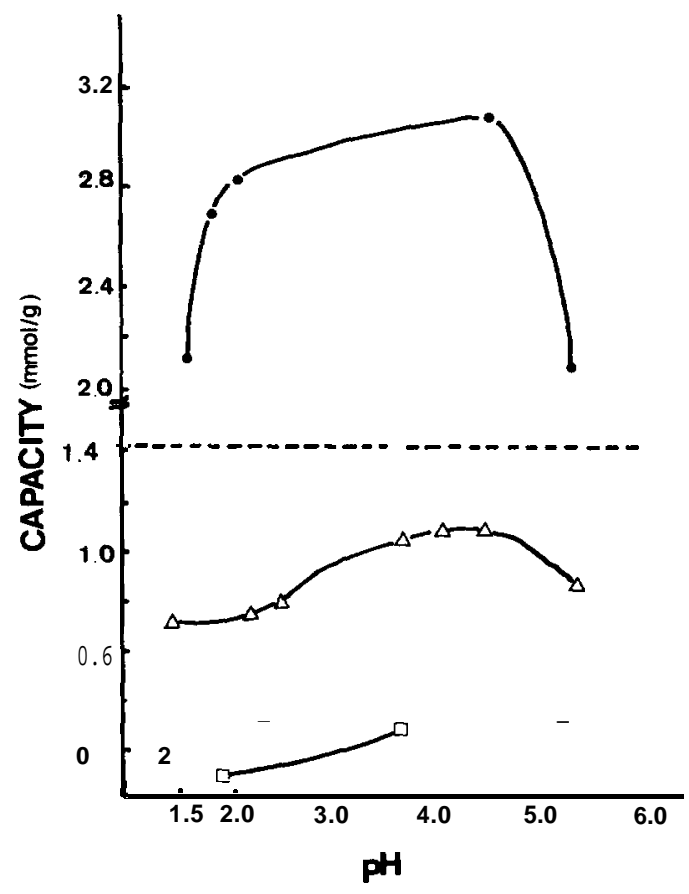

Fig. 1. Metal capacity as a function of $\mathrm{pH}$ for S-DTC resin. $\bullet=$ $\mathrm{Hg}(\mathrm{II}) ; \triangle=\mathrm{Cu}(\mathrm{II}) ; \mathrm{A}=\mathbf{C d}(\mathrm{II}) ; \square=\mathbf{Z n}(\mathrm{II})$. Dashed line: functionality of S-DTC. 
TABLE III

PRINCIPAL IR ABSORPTION BANDS $\left(\mathrm{cm}^{-1}\right)$ OF THE SYNTHESIZED RESIN AND ITS METAL COMPLEXES

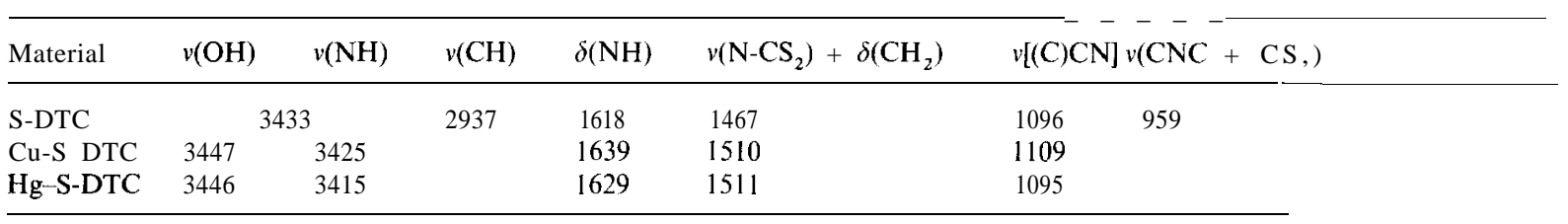

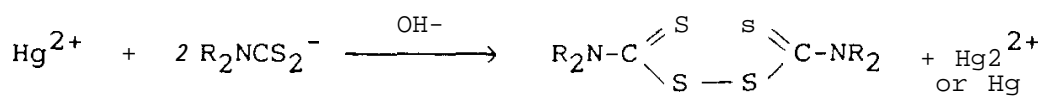

cept that for mercury, which approached saturation in the medium in the $\mathrm{pH}$ range 2-5. The metal ion capacity at $\mathrm{pH}>5$ obviously decreases, and the yellow colour of the resin turns greyish black. These effects might be due to the reducing power of the resin, undergoing the following reaction as reported by Dwyer and Mellor [9] for the reaction of $\mathrm{Et}_{2} \mathrm{DTC}$ and $\mathrm{Cu}(\mathrm{II})$ at $\mathrm{pH}>5$ shown above. All the phenomena stated above appeared to occur with the metal ions tested. However, the potential difference of the oxidation-reduction pair is not as large for $\mathrm{Cu}(\mathrm{II}), \mathrm{Cd}(\mathrm{II})$ and $\mathrm{Zn}(\mathrm{II})$ as that for $\mathrm{Hg}$ (II).

Peak positions and assignments of the IR spectra are given in Table III. Coordination of dithiocarbamate causes $v\left(\mathrm{~N}-\mathrm{CS}_{2}\right)$ to move towards higher wavenumbers and the $v\left(\mathrm{CNC}+\mathrm{CS}_{2}\right)$ peak intensity decreases. This is evidence for the coordination of the dithiocarbamate groups of the resin for each metal ion.

TABLE IV

PARAMETERS OF THE EPR SPECTRA OF Cu-S-DTC COMPLEXES AT VARIOUS $\mathrm{pH}$ VALUES

\begin{tabular}{lllll}
\hline Condition & \multicolumn{2}{l}{$\boldsymbol{g}$ Values } \\
\hline pH 1.5 & & 2.167 & 2.080 & - \\
pH 2.8 & 2.335 & 2.144 & 2.077 & - \\
pH 4.5 & 2.335 & - & 2.061 & - \\
pH 5.3 & 2.335 & - & 2.03 I & 2.012 \\
Start at pH 1.5 & & & & \\
then complexation & 2.335 & - & 2.031 & - \\
with Cu(II) at pH 4.5 & & & & \\
\hline
\end{tabular}

All the EPR spectra of the copper-loaded S-DTC resin complexes in Table IV were measured at room temperature. In the EPR spectra the $g$ value decreased with increasing $\mathrm{pH}$ of the solution. The $\mathrm{g}$ value at a higher $\mathrm{pH}$ of the solution was coincident with that for the monomeric $\mathrm{Cu}$-diethyldithiocarbamate complex (2.035) [10]. The value at a lower $\mathrm{pH}$ of the solution approached that of the $\mathrm{Cu}-$ polyiminoethylenedithiocarbamate complex (2.089) [11]. The result is rational, even though the latter was a one-dimensional polymer and the resin studied here was a three-dimensional polymer. At $\mathrm{pH}<$ 3 , one additional very broad signal results with an average $g$ value of 2.14 . This must be caused by a weak $\mathrm{Cu}-\mathrm{Cu}$ interaction resulting in the disappearance of the hyperfine structure. At $\mathrm{pH}>2.5, \mathrm{~g}$ components with an average value of 2.335 and an

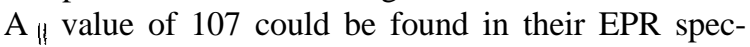
tra. This indicated the presence of $\mathrm{Cu}-0$ coordination [12]. The oxygen came from a water molecule. 'The results indicated that the presence of an unsaturated coordination of copper in the resin complexes was suitable for application in LEC.

The basic principle of LEC is that a metal ion is fixed on a solid support via a chelating ligand. The interaction occurring between a transition metal and the solute occurs with the formation of coordination bonds inside the coordination sphere of the complex-forming ion, provided that the coordination sphere of this ion is unsaturated. This applies even though various mechanisms could also be responsible for the interaction between the solute to be determined and LEC sorbents, such as ion exchange and hydrophobicity, in addition to ligand exchange. The specific coordination properties are 
TABLE V

RESULTS OF DETERMINING THE STABILITY CONSTANTS OF COPPER-RESIN COMPLEXES $\left(25^{\circ} \mathrm{C}\right)$

\begin{tabular}{lc}
\hline Parameter & Value \\
\hline $\mathrm{p} K_{\mathrm{a}}(\mathrm{EN})$ & 9.4 \\
$\mathrm{p} K_{\mathrm{a}}(\mathrm{DTC})$ & 7.0 \\
$\mathrm{pH}$ for complexation & 5.5 \\
$\mathrm{pH}$ for decomplexation & 3.5 \\
$\log K_{\mathrm{f}}$ & 10.8 \\
\hline
\end{tabular}

expected to play the most important role. As the complexation properties and complex equilibria can be characterized by the formation constant, for the calculation of the stability constants of the copper-resin complexes the following equation was used [13]:

$\log K_{\mathrm{MR}}=\log B_{j}^{\prime}-n D_{\mathrm{pH}}$

where $\boldsymbol{B}_{j}^{\prime}$ is the apparent cumulative protonation constant of the ligand, $n$ is the number of protons bound to the ligand and $D_{\mathrm{pH}}$ is the $\mathrm{pH}$ for decomplexation. The protonation constant of the synthesized resin and the $D_{\mathrm{pH}}$ values of the copper-resin complex were investigated and are given in Table $\mathrm{V}$. The stability constant of the copper-resin complex can then be calculated (Table V).

\section{Analytical application of the synthesized resin in $l i$ - gand-exchange chromatography}

Thermal stability was studied with regard to the practical use of S-DTC metal complexes as stationary phases in gas chromatography. Thermogravimetric analysis (TGA) (Fig. 2) showed that S-DTC$\mathrm{Cu}$ was very stable below $150^{\circ} \mathrm{C}$. Mass loss occurred above $160^{\circ} \mathrm{C}$, i.e., at $164.15,313.73$ and $388.51^{\circ} \mathrm{C}$, corresponding to $\mathrm{N}-\mathrm{CS}_{2}$ and $\mathrm{Si}-\mathrm{C}$ bond cleavage and loss of surface silanol groups of silica gel, respectively [14]. The S-DTC-Cu phase was also found to be very stable for longer than 25 days with continuous heating at $90^{\circ} \mathrm{C}$. These properties suggested the suitability of the resin for use as a stationary phase in gas chromatography for the separation of volatile compounds.

In LEC, a change in the concentration of ligands

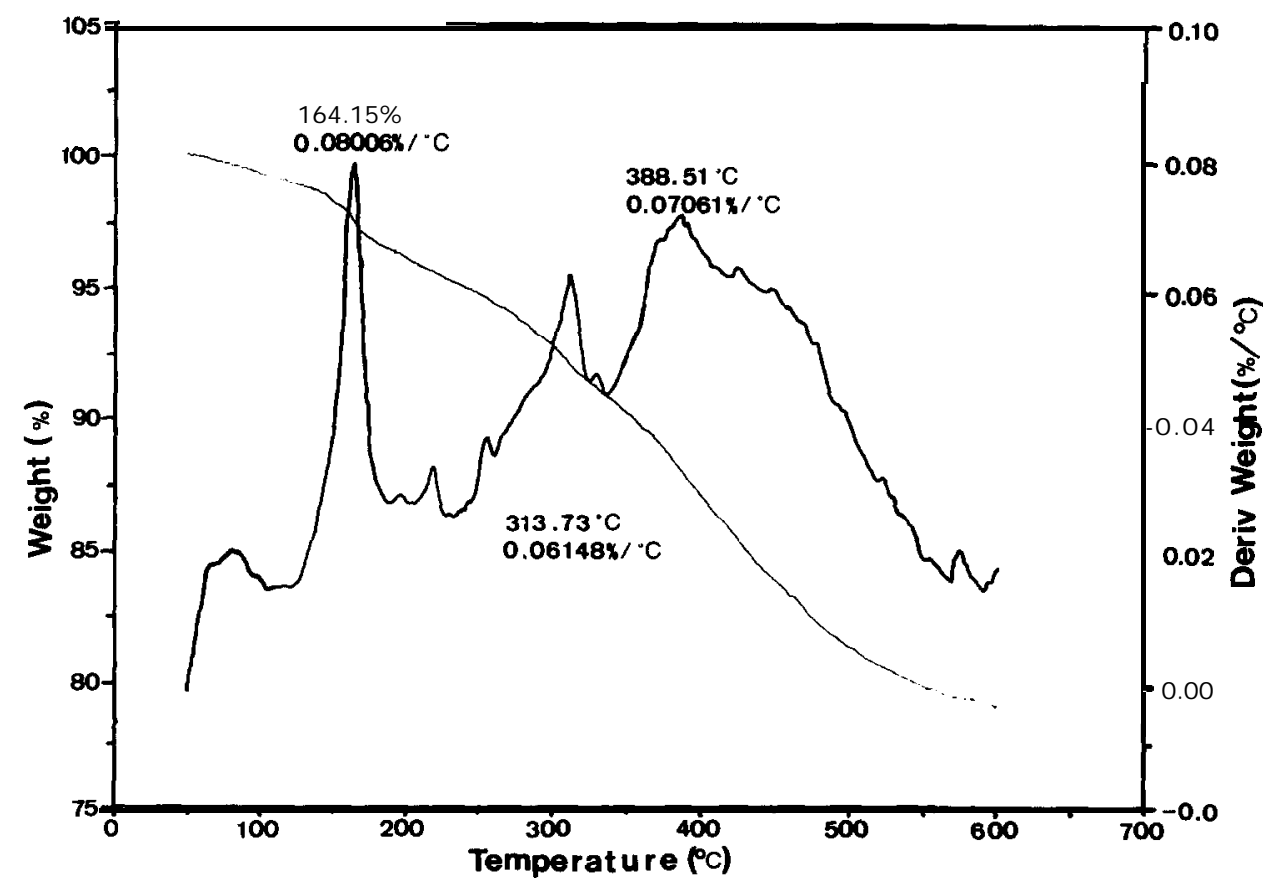

Fig. 2. TGA of S-DTC-Cu(II) complex. 

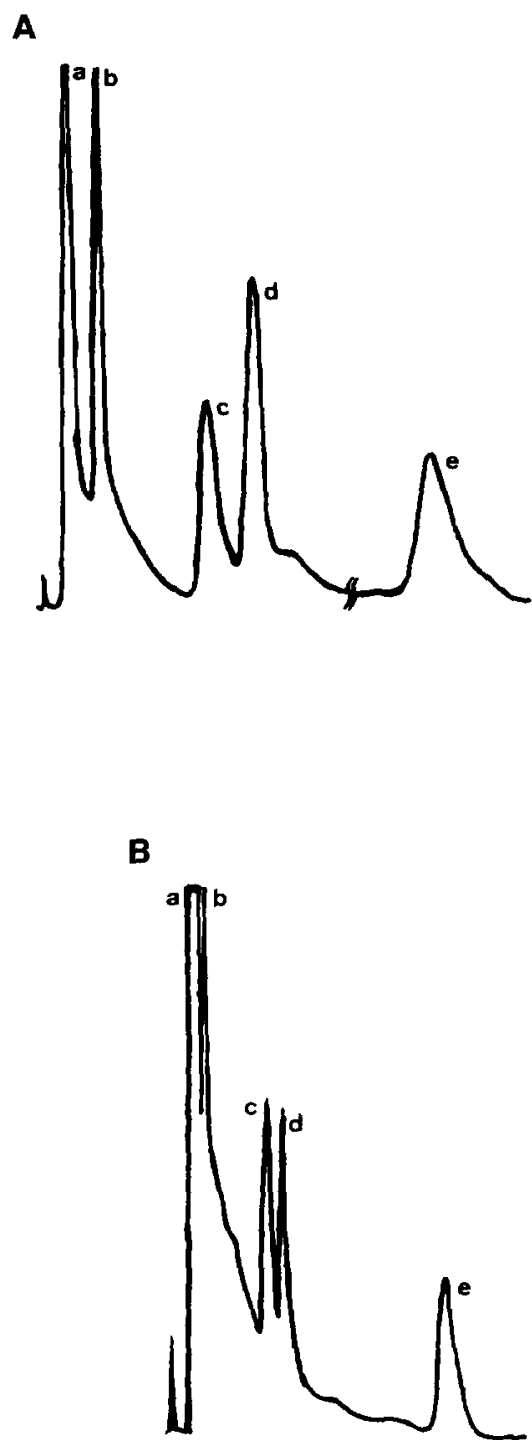

Fig. 3. Separation of mixtures. Stationary phase, S-DTC-Cu(II) complex; carrier gas, (A) nitrogen and (B) $10 \%$ (v/v) $\mathrm{NH},-\mathrm{N}$,; flow-rate, $60 \mathrm{ml} \mathrm{min}{ }^{-1}$; oven temperature, $100^{\circ} \mathrm{C}$; injection temperature, $155^{\circ} \mathrm{C}$; sample, $2 \mu \mathrm{l}, 1 \%$ in $\mathrm{CS}$. (A) Peaks: a $=\mathrm{CS}_{2}$ $\left(t_{\mathrm{R}}=2.2 \mathrm{~min}\right) ; \mathrm{b}=$ dimethyl sulphide $\left(t_{\mathrm{R}}=13.0 \mathrm{~min}\right) ; \mathrm{c}=$ allyl methyl sulphide $\left(t_{\mathbf{R}}=49.4 \mathrm{~min}\right) ; \mathrm{d}=$ diethyl sulphide $\left(t_{\mathbf{R}}=64.4\right.$ $\min )$; e $=$ diisopropyl sulphide $\left(t_{\mathrm{R}}=186.3 \mathrm{~min}\right)$. (B) Peaks: $\mathrm{a}=$ $\mathrm{CS},\left(t_{\mathrm{R}}=2.2 \mathrm{~min}\right) ; \mathrm{b}=$ dimethyl sulphide $\left(t_{\mathrm{R}}=8.8 \mathrm{~min}\right) ; \mathrm{c}=$ ally1 methyl sulphide $\left(t_{\mathbf{R}}=28.9 \mathrm{~min}\right) ; \mathrm{d}=$ diethyl sulphide $\left(t_{\mathbf{R}}=\right.$ $33.4 \mathrm{~min}) ; \mathrm{e}=$ diisopropyl sulphide $\left(t_{\mathrm{R}}=86.0 \mathrm{~min}\right)$.

in the mobile phase had a pronounced effect on the retention of sample components. The presence of ammonia in the mobile phase drastically reduced the retention of samples. The concentration of ammonia tested was $5 \%$ and $10 \%(\mathrm{v} / \mathrm{v})$ in nitrogen. The presence of ammonia in the mobile phase was found to affect not only the retention but also the peak shape (Fig. 3). A 10\% concentration of ammonia in nitrogen was chosen as the mobile phase. The effects of flow-rate and column temperature on retention when $10 \%$ ammonia in nitrogen was used as the mobile phase are shown in Figs. 4 and 5. The theoretical plate numbers in the separation of dialkyl sulphides using S-DTC-Cu as the stationary phase under various conditions are shown in Tables VI and VII.

The concentration of ammonia, flow-rate and the column temperature are important factors for the separation of sulphides, as discussed above. The factors responsible for the retention order are con-

A

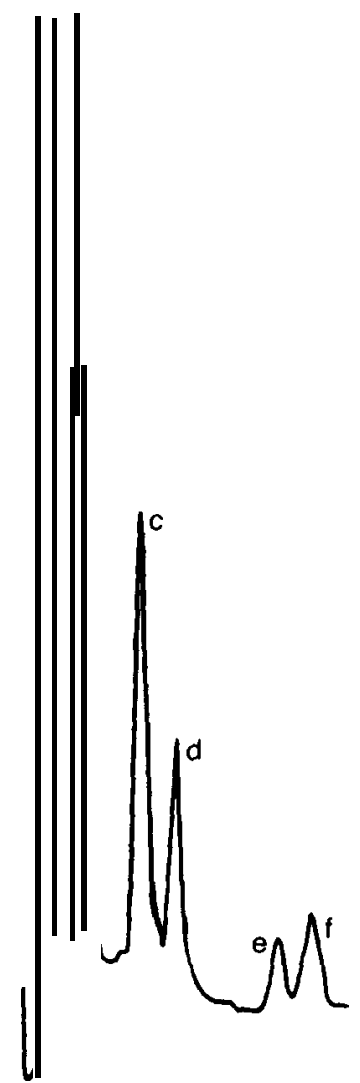

Fig. 4 
$\mathbf{B}$

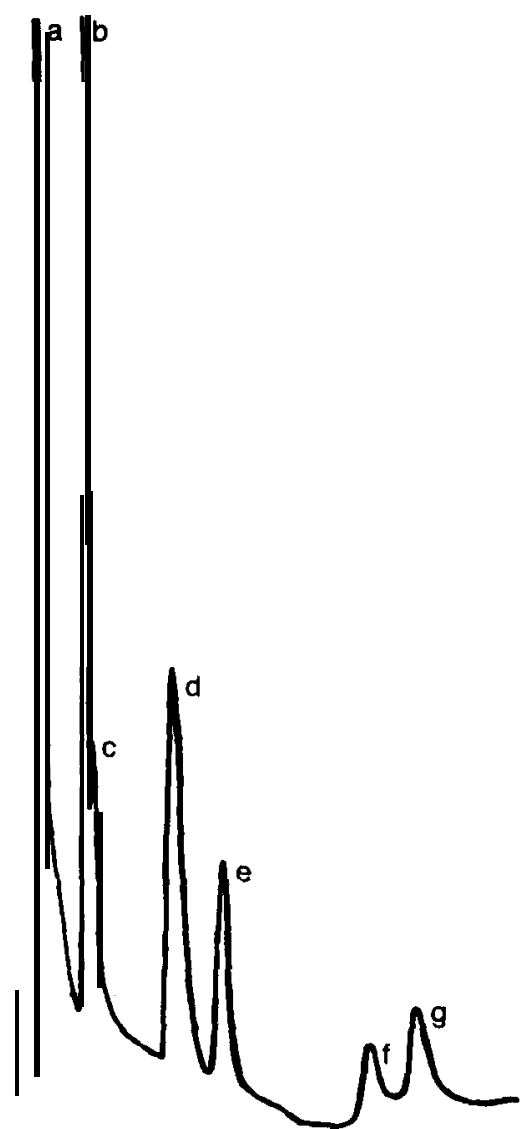

C

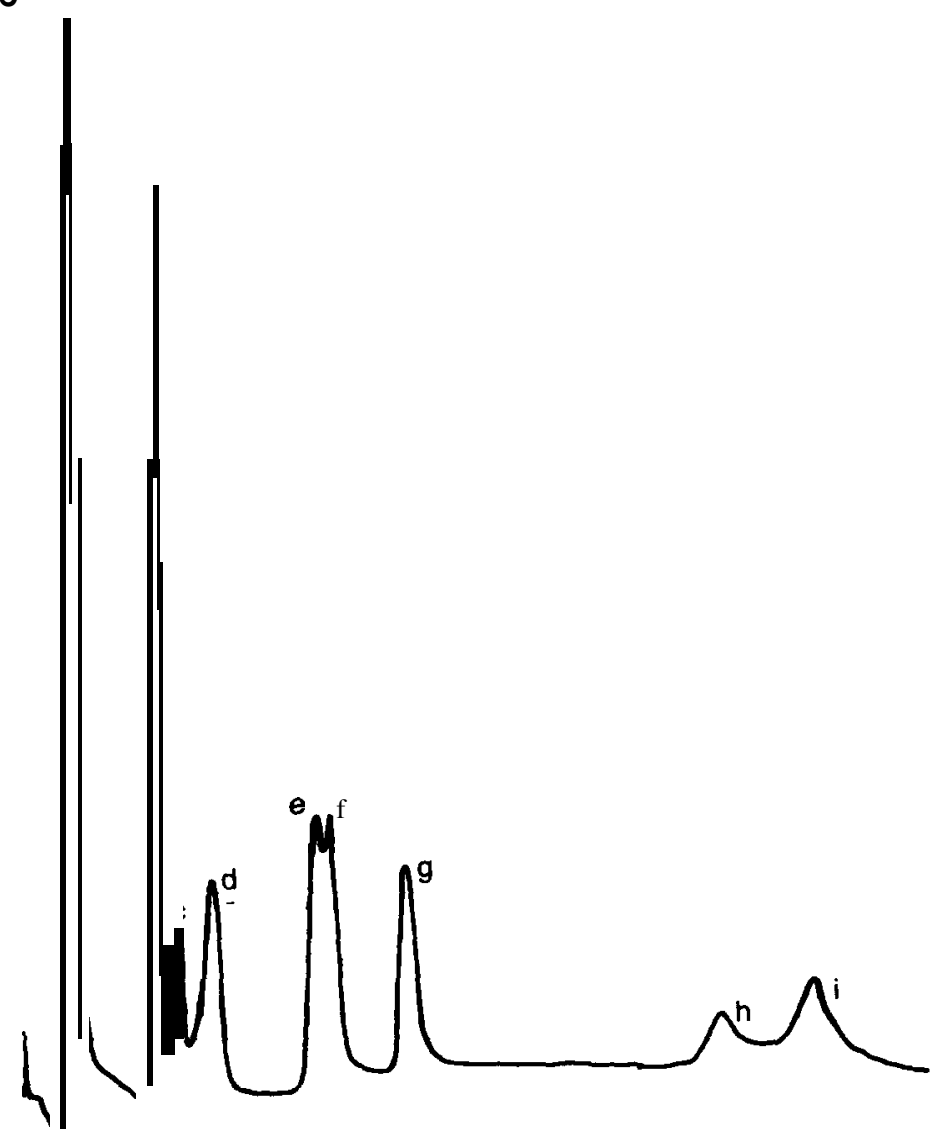

Fig. 4. Separation of hydrocarbons and dialkyl sulphides. Stationary phase, S-DTC-Cu(II) complex; carrier gas, 10\% (v/v) NH,-N,;

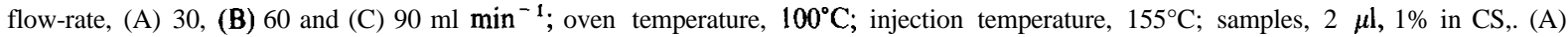
Peaks: $\mathrm{a}=\mathrm{CS},\left(\boldsymbol{t}_{\mathbf{R}}=3.0 \mathrm{~min}\right) ; \mathrm{b}=$ cyclohexane and $\mathrm{n}$-hexane $\left(\boldsymbol{t}_{\mathbf{R}}=8.5 \mathrm{~min}\right) ; \mathrm{c}=$ dimethyl sulphide $\left(t_{\mathbf{R}}=9.3 \mathrm{~min}\right) ; \mathrm{d}=\mathrm{n}-\mathrm{heptane}$ and benzene $\left(t_{\mathbf{R}}=19.1 \mathrm{~min}\right) ; \mathrm{e}=$ iso-octane $\left(t_{\mathbf{R}}=24.7 \mathrm{~min}\right) ; \mathrm{f}=$ ally1 methyl sulphide $\left(t_{\mathbf{R}}=41.4 \mathrm{~min}\right) ; \mathrm{g}=$ diethyl sulphide $\left(t_{\mathbf{R}}=47.0\right.$ min). (B) Peaks: $\mathrm{a}=\mathrm{CS},\left(t_{\mathbf{R}}=3.9 \mathrm{~min}\right) ; \mathrm{b}=$ cyclohexane and $\mathrm{n}$-hexane $\left(t_{\mathbf{R}}=11.2 \mathrm{~min}\right) ; \mathrm{c}=$ dimethyl sulphide $\left(t_{\mathbf{R}}=12.7 \mathrm{~min}\right) ; \mathrm{d}=$ $\mathrm{n}$-heptane and benzene $\left(t_{\mathbf{R}}=26.0 \mathrm{~min}\right) ; \mathrm{e}=$ iso-octane $\left(t_{\mathbf{R}}=33.3 \mathrm{~min}\right) ; \mathrm{f}=$ ally1 methyl sulphide $\left(t_{\mathbf{R}}=57.0 \mathrm{~min}\right) ; \mathrm{g}=$ diethyl sulphide $\left(t_{\mathrm{R}}=64.6 \mathrm{~min}\right)$. (C) Peaks: a $=\mathrm{CS},\left(t_{\mathrm{R}}=6.6 \mathrm{~min}\right) ; \mathrm{b}=$ cyclohexane $\left(t_{\mathrm{R}}=21.3 \mathrm{~min}\right) ; \mathrm{c}=\mathrm{n}$-hexane $\left(t_{\mathrm{R}}=25.3 \mathrm{~min}\right) ; \mathrm{d}=\mathrm{dimethyl}$ sulphide $\left(t_{\mathbf{R}}=38.6 \mathrm{~min}\right) ; \mathrm{e}=\mathrm{n}$-heptane $\left(t_{\mathrm{R}}=47.2 \mathrm{~min}\right) ; \mathrm{f}=$ benzene $\left(t_{\mathrm{R}}=49.3 \mathrm{~min}\right) ; \mathrm{g}=$ iso-octane $\left(t_{\mathrm{R}}=62.2 \mathrm{~min}\right) ; \mathrm{h}=$ allyl methyl sulphide $\left(t_{\mathbf{R}}=105.9 \mathrm{~min}\right) ; \mathrm{i}=$ diethyl sulphide $\left(t_{\mathbf{R}}=121.0 \mathrm{~min}\right)$.

TABLE VI

THEORETICAL PLATE NUMBERS OF DIALKYL SULPHIDES USING S-DTC-Cu(II) AS STATIONARY PHASE AT AN

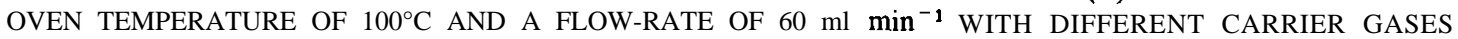

\begin{tabular}{llll}
\hline Carrier gas & Dimethyl sulphide & Diethyl sulphide & Ally1 methyl sulphide \\
\hline $10 \%$ NH,-N, & 2344 & 763 & 233 \\
Nitrogen & 108 & 694 & 195 \\
\hline
\end{tabular}


TABLE VII

THEORETICAL PLATE NUMBERS OF DIALKYL SULPHIDES USING S-DTC-Cu(II) AS STATIONARY PHASE WITH $10 \%$ NH,-N, AS CARRIER GAS AT DIFFERENT OVEN TEMPERATURES AND FLOW-RATES

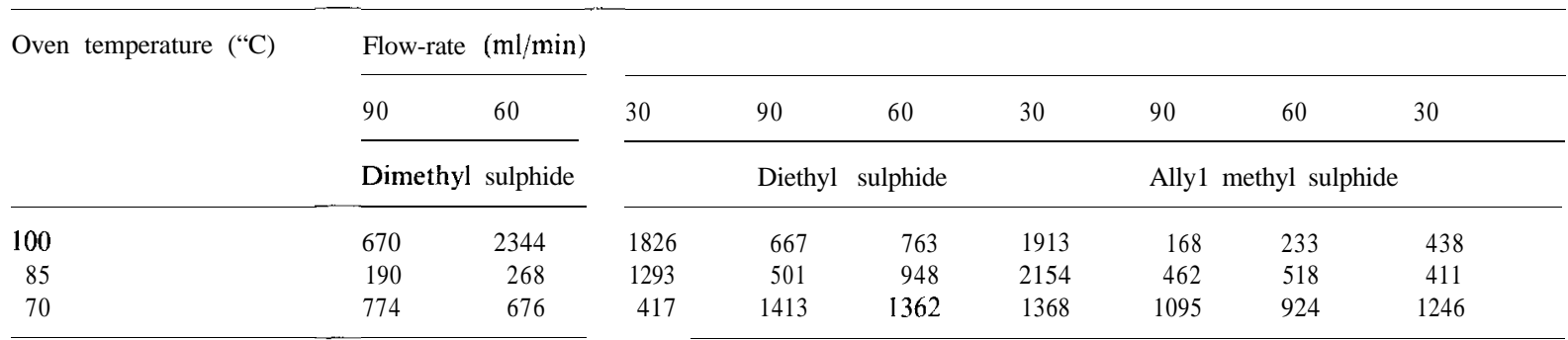

A

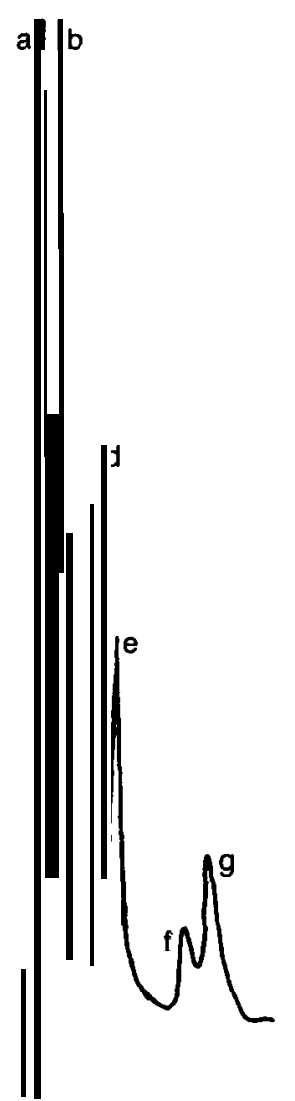

B

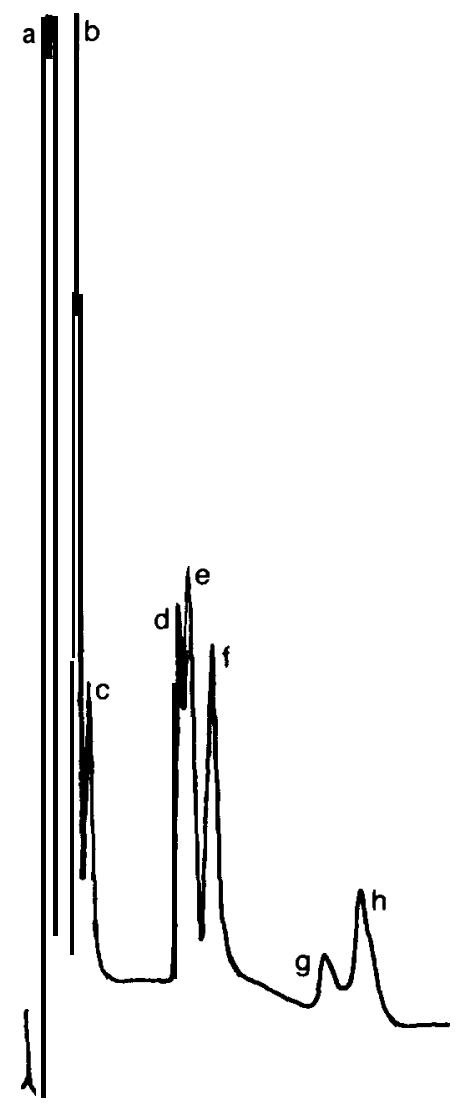

C

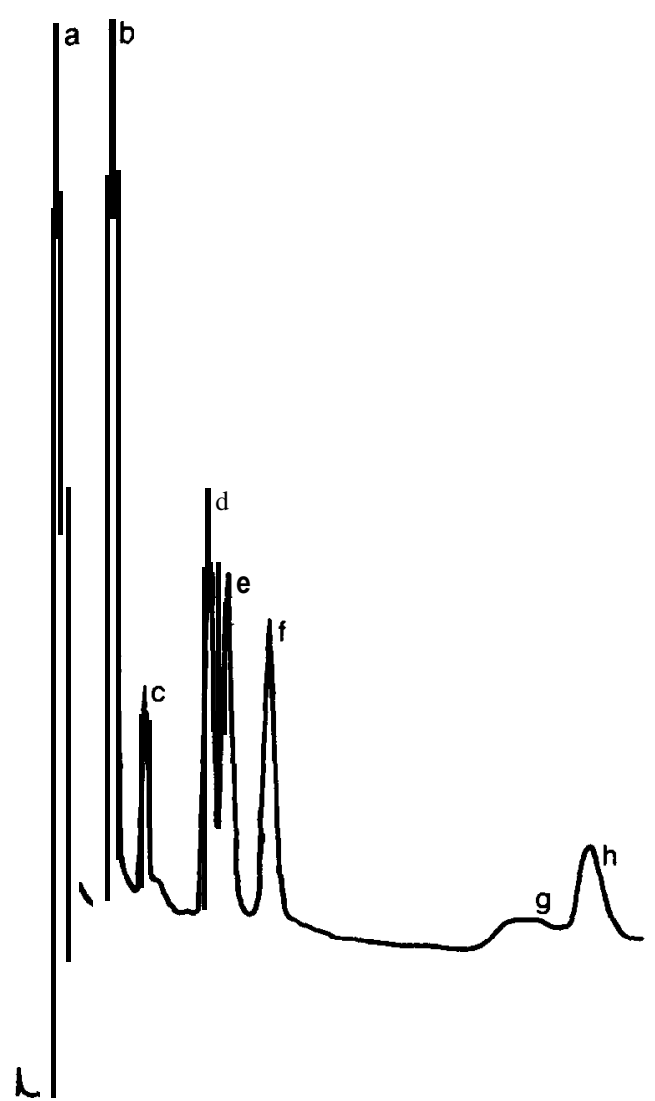

Fig. 5. Separation of hydrocarbons and dialkyl sulphides. Stationary phase, S-DTC-Cu(II) complex; carrier gas, $10 \%$ (v/v) NH,-N,; flow-rate, (A) 30, (B) 60 and (C) $90 \mathrm{ml} \mathrm{min}{ }^{-1}$; oven temperature, $85^{\circ} \mathrm{C}$; injection temperature, $155^{\circ} \mathrm{C}$; sample, $2 \mu \mathrm{l}, 1 \%$ in $\mathrm{CS}$,. (A) Peaks: $\mathrm{a}=\mathrm{CS},\left(\boldsymbol{t}_{\mathbf{R}}=2.2 \mathrm{~min}\right) ; \mathrm{b}=$ cyclohexane and $\mathrm{n}$-hexane $\left(t_{\mathbf{R}}=5.6 \mathrm{~min}\right) ; \mathrm{c}=$ dimethyl sulphide $\left(t_{\mathbf{R}}=6.9 \mathrm{~min}\right) ; \mathrm{d}=\mathrm{n}$-heptane and benzene $\left(t_{\mathbf{R}}=12.3 \mathrm{~min}\right) ; \mathrm{e}=$ iso-octane $\left(t_{\mathbf{R}}=15.0 \mathrm{~min}\right) ; \mathrm{f}=$ ally1 methyl sulphide $\left(t_{\mathbf{R}}=26.8 \mathrm{~min}\right) ; \mathrm{g}=$ diethyl sulphide $\left(t_{\mathbf{R}}=30.7\right.$ min). (B) Peaks: a $=$ CS, $\left(t_{\mathrm{R}}=3.0 \mathrm{~min}\right) ; \mathrm{b}=$ cyclohexane and $\mathrm{n}$-hexane $\left(t_{\mathrm{R}}=8.02 \mathrm{~min}\right) ; \mathrm{c}=$ dimethyl sulphide $\left(t_{\mathrm{R}}=9.1 \mathrm{~min}\right) ; \mathrm{d}=$ n-heptane $\left(t_{\mathbf{R}}=16.4 \mathrm{~min}\right) ; \mathrm{e}=$ benzene $\left(t_{\mathbf{R}}=17.8 \mathrm{~min}\right) ; \mathrm{f}=$ iso-octane $\left(t_{\mathbf{R}}=21.6 \mathrm{~min}\right) ; \mathrm{g}=$ ally1 methyl sulphide $\left(t_{\mathbf{R}}=39.8\right.$ min $) ; \mathrm{h}=$ diethyl sulphide $\left(t_{\mathbf{R}}=46.2 \mathrm{~min}\right)$. (C) Peaks: a $=\mathrm{CS},\left(t_{\mathbf{R}}=5.5 \mathrm{~min}\right) ; \mathrm{b}=$ cyclohexane and $\mathrm{n}$-hexane $\left(t_{\mathrm{R}}=15.0 \mathrm{~min}\right)$; $\mathrm{c}=$ dimethyl sulphide $\left(t_{\mathbf{R}}=20.2 \mathrm{~min}\right) ; \mathrm{d}=\mathrm{n}$-heptane $\left(t_{\mathbf{R}}=30.6 \mathrm{~min}\right) ; \mathrm{e}=$ benzene $\left(t_{\mathbf{R}}=33.5 \mathrm{~min}\right) ; \mathrm{f}=$ iso-octane $\left(t_{\mathbf{R}}=40.5 \mathrm{~min}\right) ; \mathrm{g}=$ allyl methyl sulphide $\left(t_{\mathbf{R}}=81.1 \mathrm{~min}\right) ; \mathrm{h}=$ diethyl sulphide $\left(t_{\mathbf{R}}=92.8 \mathrm{~min}\right)$. 
sidered, on the basis of the chromatograms, to be as follows. In LEC, the ligand-exchange equilibrium and the basicity of the sulphur atom of a sulphide are thought to be responsible for the elution order. Other factors should exist that affect the elution order, as the basicities of dialkyl sulphides are not very different from one another. Branching of the alkyl group inhibits the copper-sulphur coordination and causes weak retention. Di-sec.-butyl sulphide (retention time $>180 \mathrm{~min}$ ) and di-tert.-butyl sulphide (retention time $>130 \mathrm{~min}$ ), for example, were eluted in this order (not shown in Fig. 6). For sulphides having the same carbon number and which possess two alkyl groups, that which has the longest alkyl chain was most strongly retained. Diethyl sulphide and methyl ally1 sulphide, for example, were eluted in this order (Fig. 4). The differ-

\section{A}

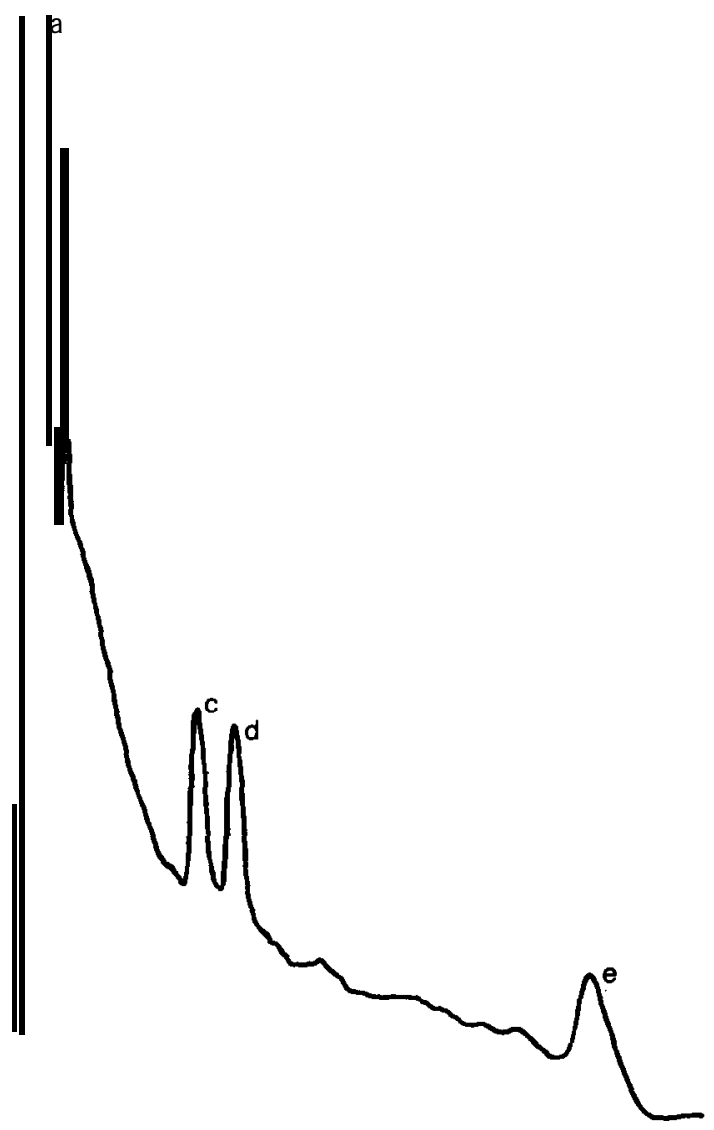

ence in the vapour pressure of samples at a given column temperature was an important factor in determining the elution order, because the retention of a sample molecule was based on its gas-solid distribution. The boiling point of dimethyl sulphide is the lowest among the sulphides studied, hence in most separations dimethyl sulphide was eluted first.

The determination of dialkyl sulphides by the proposed ligand-exchange GC method was also studied (Fig. 6). The calibration graphs are shown in Fig. 7. As these compounds were highly volatile and difficult to handle accurately, the correlation coefficients were lower than expected, with values of 0.9983 (dimethyl sulphide), 0.9963 (ally1 methyl sulphide), 0.9857 (diethyl sulphide) and 0.9970 (diisopropyl sulphide), based on the average of three measurements of the sample mixture.

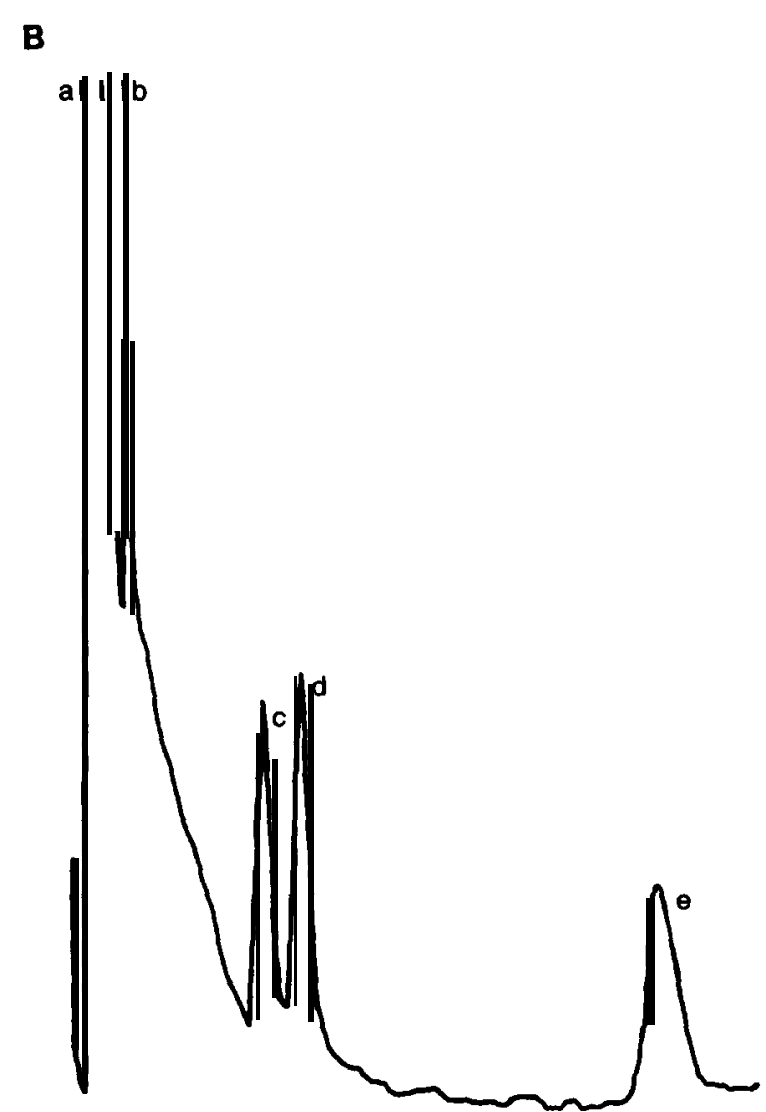

Fig. 6. 
C

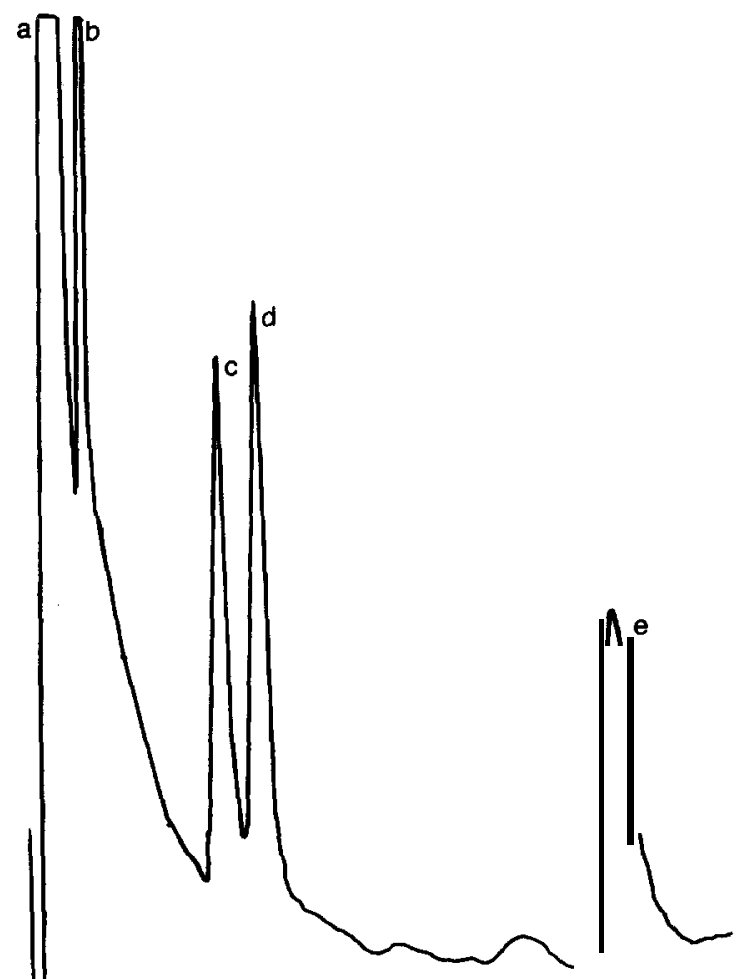

Fig. 6. Separation of mixtures. Stationary phase, S-DTC-Cu(II) complex; carrier gas, $10 \%$ (v/v) NH,-N,; flow-rate, $60 \mathrm{ml} \mathrm{min}^{-1}$; oven temperature, $100^{\circ} \mathrm{C}$; injection temperature, $155^{\circ} \mathrm{C}$. (A) Peaks: a $=\mathrm{CS},\left(t_{\mathbf{R}}=2.4 \mathrm{~min}\right) ; \mathrm{b}=\operatorname{dimethyl~sulphide}\left(t_{\mathrm{R}}=9.3 \mathrm{~min}, 1.06 \mu \mathrm{g}\right)$; $\mathrm{c}=$ ally1 methyl sulphide $\left(t_{\mathrm{R}}=32.3 \mathrm{~min}, 1.59 \mu \mathrm{g}\right) ; \mathrm{d}=$ diethyl sulphide $\left(t_{\mathrm{R}}=38.7 \mathrm{~min}, 1.17 \mu \mathrm{g}\right)$; e diisopropyl sulphide $\left(t_{\mathrm{R}}=110.5\right.$ min, $1.35 \mu \mathrm{g})$. (B) Peaks: $\mathrm{a}=\mathrm{CS},\left(t_{\mathbf{R}}=2.4 \mathrm{~min}\right) ; \mathrm{b}=$ dimethyl sulphide $\left(t_{\mathbf{R}}=9.3 \mathrm{~min}, 1.99 \mu \mathrm{g}\right)$; $\mathrm{c}=$ ally1 methyl sulphide $\left(t_{\mathbf{R}}=32.6\right.$ $\min , 2.63 \mu \mathrm{g}) ; \mathrm{d}=$ diethyl sulphide $\left(t_{\mathbf{R}}=39.3 \mathrm{~min}, 2.67 \mu \mathrm{g}\right) ; \mathrm{e}=$ diisopropyl sulphide $\left(t_{\mathbf{R}}=112.6 \mathrm{~min}, 2.71 \mu \mathrm{g}\right)$. (C) Peaks: a $=$ CS, $\left(t_{\mathrm{R}}=2.4 \mathrm{~min}\right) ; \mathrm{b}=$ dimethyl sulphide $\left(t_{\mathrm{R}}=9.3 \mathrm{~min}, 4.78 \mu \mathrm{g}\right) ; \mathrm{c}=$ ally1 methyl sulphide $\left(t_{\mathbf{R}}=32.8\right.$ min, $\left.5.45 \mu \mathrm{g}\right) ; \mathrm{d}=$ diethyl sulphide $\left(t_{\mathrm{R}}=39.6 \min .5 .10 \mu \mathrm{g}\right) ; \mathrm{e}=$ diisopropyl sulphide $\left(t_{\mathrm{R}}=111.6 \mathrm{~mm}, 5.40 \mu \mathrm{g}\right)$.

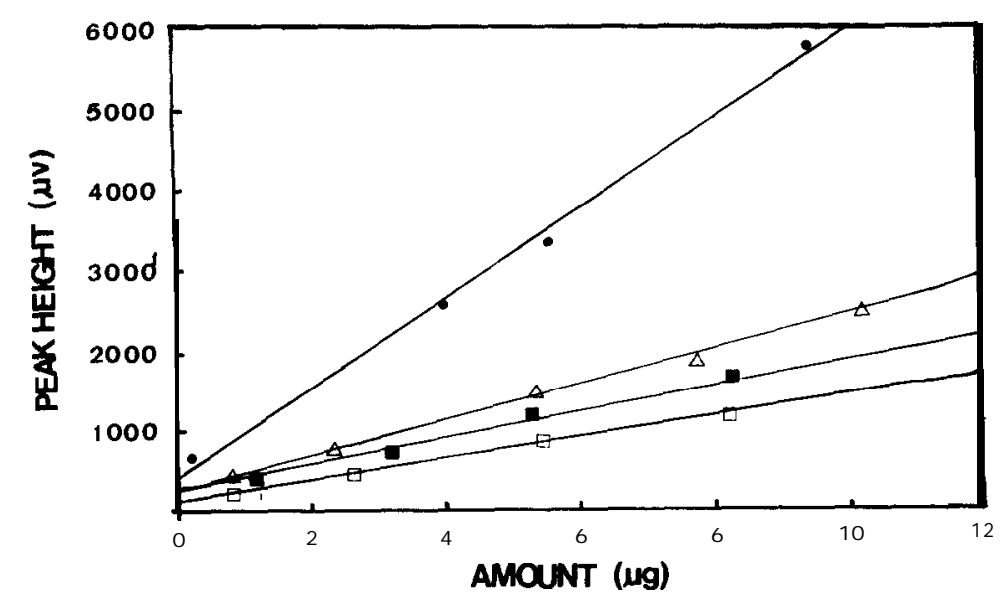

Fig. 7. Determination of dialkyl sulphides by ligand-exchange GC. Oven temperature, $100^{\circ} \mathrm{C}$; carrier gas, $10 \%(\mathrm{v} / \mathrm{v}) \mathrm{NH},-\mathrm{N}$,; flow-

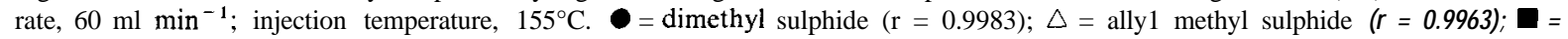

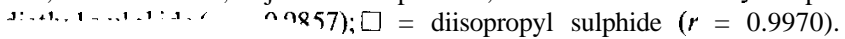




\section{CONCLUSIONS}

The synthesized dithiocarbamate resin has been demonstrated to have a high affinity for the metal ions studied. The thermal stability of the resin-metal complexes made them very suitable for use as stationary phases for the ligand-exchange GC for the separation of dialkyl sulphides. The results showed that the elution order of samples was dependent on the surface structure of the matrices, the central metal ion, the complex-forming ability of the sample and the steric hindrance to complex formation.

\section{ACKNOWLEDGEMENT}

Financial support of this work by the National Science Council of Taiwan is gratefully acknowledged.

\section{REFERENCES}

1 Z. Marczenko, Separation and Spectrophotometric Determination of Elements, Ellis Horwood, Chichester, 1985.

2 G. V. Myasoedova and S. B. Savvin, CRC Crit. Rev. Anal. Chem., 17 (1987) 1.

3 F. Helfferich, Nature, 189 (1961) 1001.

4 N. W. F. Nielen, H. E. van Ingen, A. J. Valk, R. W. Frei and U. A. Th. Brinkman, J. Liq. Chromatogr., 10 (1987) 617.

5 H. Takayanagi, 0. Hatano, K. Fujimura and T. Ando, Anal. Chem., 57 (1985) 1840.

6 V. A. Davankov, J. D. Navratil and H. F. Walton, Ligand Exchange Chromatography, CRC Press, Boca Raton, FL, 1988.

7 D. A. Skoog and D. M. West, Fundamentals of Analytical Chemistry, Saunders College Publishing, New York, 5th ed., 1988.

8 G. D. Thorn and R. A. Ludwig, The Dithiocarbamates and Related Compounds, Elsevier, Amsterdam, 1962.

9 F. P. Dwyer and D. P. Mellor, Chelating Agents and Metal Chelates, Academic Press, New York, 1964.

10 H. R. Gersmann and J. D. Swalen, J. Chem. Phys., 36 (1962) 3221.

11 P. C. H. Mitchell and M. G. Taylor, Polyhedron, 1 (1982) 225.

12 B. Prabhakar and P. Lingaiah, Polyhedron, 9 (1990) 805.

13 R. Hering, Chelatbildende Ionenaustauscher, Academie Verlag, Berlin, 1967.

14 D. E. Leyden, Silanes, Surfaces, and Interfaces, Gordon and Breach, New York, 1986, p. 29. 